\title{
Scientific and educational vector of the social and human capital network component formation
}

\author{
Olga Yarmak $^{1,{ }^{*}}$, Ekaterina Strashko ${ }^{1}$, Mariya Bolshakova ${ }^{1}$, Pavel Deryugin ${ }^{2}$, and Veronika \\ Yarmak $^{2}$ \\ ${ }^{1}$ Sevastopol State University, Sevastopol, Russia \\ ${ }^{2}$ Saint Petersburg State University, Saint Petersburg, Russia
}

\begin{abstract}
The authors raise the problem of the scientific and educational vector of the formation of the network component of social and human capital in Russian regions. The development of the network component is becoming one of the policy directions for the formation of the region's human capital through the creation of certain network centres. The emerging network connections of world-class scientific and educational centres in Russian regions are analyzed, which create conditions for transforming the existing human potential of the territory into the human and social capital of the country. Based on the definition of social capital by P. Bourdieu and M. Paldam as a group resource for obtaining social connections, the authors analyze the process of forming network connections between the educational, scientific environment of the region, its business community and government bodies at the sites of world-class scientific and educational centres operating in Russia, which is the basis for the formation of the social capital of the territory. The conclusions of the study are to determine the structure of ties in the scientific and educational vector of social and human capital through the functioning of network RECs, which become interregional coordination structures for the scientific and educational space of the country.
\end{abstract}

\section{Introduction}

Human and social capitals are closely related to each other, since in order to possess social capital, a person must be connected with other people, and communications and social ties are the source of social capital. In this regard, in the modern world, the issue of creating consortia that unites the capabilities of various organizations and groups of people has become topical. It is consortia, both scientific and industrial, that are able to build up social and human capital and form their network component.

The network component is provided by a social mechanism that connects social ties between the internal elements of human capital and carriers of other capitals. It can be defined as the ability of an individual to form and develop social ties between collective

\footnotetext{
*Corresponding author: olga_yarmak@inbox.ru
} 
and individual bearers of capital. The degree of integration and sustainability of human capital depends on the density of social ties, that is, it is the network component that ensures the social integration of the human capital of the territory.

The network component of human capital functions at four levels: personal, group, regional and country or federal. The integrity of human capital at all these levels is ensured by its network component, which is formed in the process of executing decisions of state policy and implementing national projects of the state.

The development of the network component of capital is becoming one of the directions of the regional human capital development policy through the creation of certain network centres.

The main resource for the formation, development, preservation of the network component of human capital is social capital, which is understood as a set of social ties created and existing in human collectives; norms and rules that govern relationships between people that ensure group cohesion and solidarity. All the listed components of social capital can participate in the formation of its network element of human capital, and, conversely, a developed network component can increase social capital [1-3].

An important priority in the development of the network component of capital is the possibility of forming a system for transforming the existing human potential into human capital. Today in Russia there is a shortage of personnel with such abilities - increasing the "profitability" of the potential by increasing it. A similar situation occurs at the regional level. Consequently, network connections should be formed aimed at creating, preserving, producing the conditions necessary for realizing the potential and converting it into capital in all territories of the country.

The system of education and science is both an environment for the accumulation of social capital and the strengthening of the unity of the nation and civil society. This, in turn, serves as a basis for the formation of public trust [4], which is the result of a person's confidence in the future, guarantees of the availability of public resources and the level of security. Thus, universities are becoming crossroads of social cooperation, forming an atmosphere of social trust around them.

The higher school promotes the development of cooperation both in the learning process and after graduation, forming human consortia and uniting people working in various spheres of the economy, and linking them outside of formal structures. This cooperation ultimately leads to an increase in the effectiveness of state power, promotion of civic engagement, smoothing out inequality, reducing the scale of social exclusion and corruption - for the benefit of society, the state and the market [5].

Such network connections are possessed by world-class scientific and educational centres, which, on the one hand, form network communications between the educational, scientific environment of the region, its business community and authorities, on the other hand, they create conditions for transforming the existing human potential of the region into human and social capital of the country.

\section{Materials and Methods}

Social capital determines the quality of social ties in a society. Sometimes it is considered as a characteristic of society that determines the quality of life in a particular country.

Social capital is a concept introduced by Pierre Bourdieu to denote social ties that can act as a resource for obtaining benefits. In Bourdieu's concept, social capital is an exclusively group resource [6]. The authors used this approach as the basis for the research methodology.

Indicators for measuring social capital are "proximal" - the results of the influence of social capital on certain aspects of people's lives associated with networks, trust and 
reciprocity in relationships, and "distal" - the results of the influence of social capital, which are not directly related to its key components. For the measurement, social capital indices are used, which are constructed on the basis of a certain system of indicators. In particular, in quantitative studies, when calculating social capital, the trust index is calculated, as well as the number of groups (associations, public organizations, etc.) and their members, which are united by the civil society development index.

The Danish social economist Martin Paldam proposed three pillars for building social capital: trust, ease of cooperation, and networking. According to game theory, social capital is the propensity for cooperative decisions in games with prisoners' dilemmas. The scientist measures social capital, focusing on social networks as the number of relationships that an individual has, and describes the process of striving for the dream of social capital, which consists in the fact that everyone is trying to capture aspects of the same phenomenon, as a result of which the hidden variables of social connections. He introduces an assessment of ease of cooperation - the number of participants in voluntary organizations (the density of voluntary organizations) and the strength of relationships within the network. This approach to measuring social capital is closely related to measuring trust: how much people trust each other, how much their desire to cooperate and enter into voluntary cooperation and consortia depends [7-9].

Russian economist Alexander Auzan, studying the level of social capital, asks the question why in some countries different groups produce a lot of public goods, while in others - few. He explains this by the costs of social communications, which are an indicator of social capital, indicating the level of mutual trust and honesty in society. The most important way to build up social capital is the growth of social ties and the level of public trust.

Auzan talks about two types of social capital. The first is called bonding, from the English word "bond" - "bond". This is a kind of enclosure within one group of people: I trust, but only my own. Another type of capital is bridging, from the English word "bridge" - "bridge". It is more conducive to economic growth, because it allows you to build connections between different groups of people. But it is very difficult and difficult to accumulate and realize bridging social capital. For the accumulation of bridging social capital, the growth of trust between groups, the harmonization of formal and informal institutions is required, the development of public trust and negotiability as not a manifestation of weakness, but a social formula [10]

The challenges facing the process of "developing", "accumulating" and "investing" human capital in Russian society are "connecting human capital" to all processes of the country's development. To do this, we need to make sure that our human capital becomes the driver of the economy, it is necessary to create its social basis - a network component and communication between students of universities and their graduates, between universities and employers.

The authors identified the main category of analysis as the network social component of the region's human capital or social capital, which depends on a number of factors: available human, natural, material, financial, innovative and other resources, resources to improve the quality of life of the population, socio-demographic indicators, migration situation, the level of health care, qualification characteristics of labour resources, indicators of labor force mobility, employment and unemployment, cultural and historical characteristics of the region, the specifics of the way of life [11].

The purpose of our study was to analyse the process of forming network connections between the educational and scientific environment of the region, its business community and authorities at the sites of world-class scientific and educational centres operating in Russian regions, which serves as the basis for the formation of the social capital of the territory. 
To achieve the set goals within the framework of the research project, expert interviews were carried out with representatives of education, science, business and authorities of the Belgorod and Samara regions, where the World-class Scientific and Educational Centre "Innovative Solutions in the Agroindustrial Complex" (Belgorod) and the REC "Engineering of the Future "(Samara). Experts participating in the study are attracted to the sites of these RECs as educational, scientific members, industrial partners, and employees. The expert interview included 4 blocks: an assessment of the national project "Science and Universities", its importance for the functioning of REC, understanding of network interaction within the REC and REC site with the federal centre, REC and universities, analysis of the student's competence profile and his life trajectories, citizenship as a future employee REC.

\section{Results and Discussion}

The collected expert interviews of participants in world-class scientific and educational centres in Belgorod and Samara reflected the assessments of the significance of the Science and Universities national project for regional development and for the work of REC, the formation of network interaction between participants, industrial partners at the REC and REC with the federal centre.

The significance of the Science and Universities national project is assessed as a new chapter in the history of Russia's scientific breakthrough, which will increase the level of Russian developments in priority areas and increase the population's interest in science, education, and innovative development. As a result of the implementation of the national project, an interuniversity network will be formed and "stronger ties will be established between universities in different regions at all levels, and an open mechanism for regional lobbying of projects will be created."

Speaking about the significance of the national project "Science and Universities" for the Russian regions, the experts talked about "achieving a scientific breakthrough in order to create a socio-cultural environment for high-tech solutions, which will lead to the creation in Russia of not a social, but a high-tech state. a kind of " scientific and technological sovereignty".

The RECs themselves are assessed by them "not as ready-made ecosystems, but as a kind of manual adjustment of interaction, a system of synergistic interaction between science and education"; "REC is not only about growing human capital, REC is about creating its network component - science, business, education". At the same time, the format of interaction between REC and the federal centre should not be based on domination, but on reassembling federal processes at the local level: "there should be a reboot, through the REC, tasks that the President entrusts to the government should be broadcast, and REC performs them and provides feedback". Thus, the REC expert community is perceived as a "mediator" between regional processes and federal requirements, and therefore the format of interaction between REC in the region and the federal centre is most effective precisely in this perspective. REC should work as a "single window" for representatives of education, science, business, which will effectively carry out federal tasks. But at the same time, the interaction between REC and the federal centre should be based on regional processes: all changes should ensure an improvement in the quality of life of most people on a certain territory, and this criterion should be the most important.

The importance of the network component is evidenced by expert assessments about the understanding of the very idea of REC and its further functioning: "it is a system of cooperation between science, education, business and government in the region; one of the REC tasks is to build successful interaction between those who are engaged in the 
development of innovative products and technologies, those who can introduce these developments / technologies into production and those who regulate the processes of regional development ". Considering the network characteristics of REC, experts refer to it as a "platform for experiments and case creation".

Experts unanimously expressed the opinion that REC is a factor in the formation and development of the region's human capital from the internal potential, that is, a platform for "growing" personnel. Here the youth vector is important: work with schoolchildren, students and young scientists should be carried out in order to actively involve them in science and in the activities of RECs themselves.

Representatives of business and industrial partners consider REC as "a new trend in business and production, as a basis for sustainable economic, resource and social development of the region and a factor in sustainable development of the territory." REC is perceived as "a bridge that can help to obtain new scientific developments, implement their investment and implementation."

In fact, REC is a bridge, bridge build-up of social and human capital of the region and the country as a whole: "REC is not just a concentration of intellectual resources, but an opportunity to establish network interaction"; "REC is not an institution, not an organization, it is rather a platform for the exchange of experience, ideas, contacts, it is a way of interaction, within the framework of which communication takes place on the REC platform itself between representatives of the expert community".

Experts believe that in order to achieve the set goals, REC must "create a new innovation space in regions and cities - interuniversity space, which will be built directly into the city. At the same time, the university / university should become an ecoenvironment, when not startups, but real companies that set trends work inside the university ". Business participants of scientific and educational centres consider them as a tool for scientific development and investment in a broad sense: "Now REC has become a tool for working with new solutions, a tool to support a caring person, business, student who wants to develop".

For development in the flagship universities of REC, it is necessary:

- design an entrepreneurial environment, which will allow researchers to focus their attention not only on scientific research, but also on the possibility of commercializing finished products;

- carry out technology transfer and successfully apply the results of scientific research in the REC network.

The entrepreneurial environment in a flagship REC institution should be expressed:

- in the number of entrepreneurial programs;

- in the number of companies with which the university has agreements on cooperation in the entrepreneurial sphere (including agreements on the creation of basic departments);

- in the number of participants in university programs aimed at the development of entrepreneurship;

- in the number of university centres in the field of engineering;

- in the development of an entrepreneurial culture and the attraction of successful entrepreneurs to the university.

The implementation of technology transfer in a flagship REC should be expressed:

- in the amount of funds for research and development, attracted from extrabudgetary sources;

- in the amount of funds received through the use of the results of intellectual activity;

- in the amount of investments attracted by operating small innovative enterprises created at the university;

- in the amount of funds received through the provision of services / performance of work for external contractors in the field of engineering. 
The pivotal university REC will be able to become a full-fledged factor of the socioeconomic environment of the region, provided that its needs are met, "the implementation of the results of activities in the daily life of the inhabitants of the region", an increase in the number of jobs in existing small innovative enterprises created under it.

\section{Conclusion}

Currently, there are 15 world-class scientific and educational centres in Russia, which include 35 regions, where half of the country's population lives. Scientific and educational centres in the regions have been operating for two years. In the first two years, 10 scientific and educational centres were created, and the first 5 of them are dynamically moving and are already showing the first results, which is expressed in the cooperation of scientific and educational organizations in these regions, the formation of a new scientific agenda, closer ties with business. The expected level of network interaction at REC sites has not yet been achieved, but its different quality is already being recorded and the start of implementation of specific technological projects.

The scientific and educational vector of the formation of the network component of social and human capital through the functioning of a world-class scientific and educational centre in the region should have two results:

1. REC should encourage talented youth to come to the region and gain a foothold there, working in the scientific and educational sector, universities, research institutes, business companies, occupying high-tech jobs; creating conditions for migration flow from region to region, from capitals to regions, from regions to capitals. Therefore, the first task of REC is to create the most comfortable conditions for the development and self-realization of talents, school and university graduates.

2. REC should participate in the socio-economic development of the region through the launch of new technological projects, that is, the specifics of its functioning should consist in creating a different quality of network interaction between the main participants in scientific and technological development - universities, research institutes, business and the region itself.

Thus, the network RECs are becoming interregional coordination structures for the scientific and educational space of the country. But at the same time, it is necessary to take into account the existing mental and scientific and technological differences between regional opportunities and federal tasks.

For the effective functioning of a world-class REC, universities should become centres of regional management: not only representatives of the scientific sphere, but also industrial partners unite around the REC. Networking at the REC site should be filled with specific projects created by consortia and agreements. Networking should not be the development of the human potential of the region, but the augmentation of its social and human capital, while a significant condition is that the region demonstrates a financial model with the participation of a business partner.

At the REC site in the region, strategic plans of universities should be implemented to increase the competitiveness of the region, improve the quality of life of its population, and the university should act as an attraction point for both human resources and technologies and innovations. Scientific organizations, government and business unite around the university, which allows transforming the socio-cultural environment of the region and forming an ecosystem around the university. This is the logic behind the world-class REC model. 


\section{Acknowledgements}

The study was carried out with the support of the Russian Foundation for Basic Research within the framework of the scientific project No. 19-29-07443/20 "Scientific and educational centres as a factor in the formation of human capital in Russia: the format of creating world-class scientific and educational centres in accordance with the Presidential Decree" On national goals and strategic objectives of the development of the Russian Federation for the period up to 2024 "

\section{References}

1. J. S. Coleman, American Journal of Sociology 94, 95-120 (1999)

2. N. Lin, Social Capital. A Theory of Social Structure and Action (2001)

3. R. Inglehart, M. Basáñez, A. Moreno, Human Values and Beliefs: A Cross-Cultural Sourcebook: Political, Religious, Sexual, and Economic Norms in 43 Societies (1998)

4. F. Fukuyama, Trust. The Social Virtues and the Creation of Prosperity (1995)

5. Yarmak Olga, Shkaiderova Tatyana, Strashko Ekaterina, Bolshakova Maria, Garas Lyudmila, Institution of higher education transformation and society's response to distance learning during the Covid 19 pandemic, E3S Web of Conferences 244, 11043 (2021)

6. P. Bourdieu, The Forms of Capital. In Richardson J. ed. Handbook of Theory and Research for the Sociology of Education (1986)

7. M. Paldam, G. T. Svendsen, Trust, Social Capital and Economic Growth: An International Comparison (2006)

8. M. Paldam, Social capital and social policy. Arusha Conference, "New Frontiers of Social Policy" - December 12-15 (2005)

9. M. Paldam, Journal of Economic Surveys 14(5), 629-654 (2008)

10. A. Auzan, Economy of everything. How institutions define our life, 160 (2014)

11. P. P. Deryugin, O. V. Yarmak, E. V. Strashko, E. V. Strashko, V. E. Yarmak, V. A. Glukhikh, Revista inclusions 7, 178-197 (2020) 